\title{
Medicina, Narrativa y Ser
}

\author{
Patricio Santillán-Doherty凶 \\ Editor en Jefe de la Revista Neumología y Cirugía de Tórax; Director Médico, Instituto Nacional de Enfermedades Respiratorias \\ Ismael Cosío Villegas, Ciudad de México. \\ Trabajo recibido: 20-VI-2014, aceptado: 20-VI-2014
}

\begin{abstract}
"Todos estamos en la alcantarilla, pero algunos estamos mirando a las estrellas". Lord Darlington en: El Admirador de Lady Windermere (La Historia de una Buena Mujer). Oscar Wilde, 1892.
\end{abstract}

El primer cuatrimestre del presente año se presentó como uno especialmente problemático para los que laboramos en el Instituto Nacional de Enfermedades Respiratorias debido a un incremento desmedido en la afluencia de pacientes graves afectados por influenza. Es suficiente ver la gráfica respectiva que aparece en la sección de Mundo Respiratorio en este mismo número de NCT para entender el problema; si bien, se aprecia en la misma gráfica una tendencia estacional similar a la de otros años, basta seguir la tercer línea (roja) que corresponde a pacientes que requirieron ventilación mecánica invasiva para aquilatar el problema: la cantidad de pacientes graves este año incluso sobrepasó el presentado en el 2009. Las áreas críticas (urgencias y terapia intensiva) fueron insuficientes para manejar el flujo de pacientes, los cuales ameritaron ser colocados en áreas de hospitalización convencional reconvertidas con equipamiento para su manejo. Así, por cada paciente en ventilación mecánica en área crítica (urgencias/terapia intensiva), hubo entre 1-1.5 pacientes de características similares en las áreas de hospitalización convencional.

Esta situación representó una presión importante al sistema institucional desde un punto de vista económico y, principalmente, laboral. El personal médico, de enfermería, técnico y de apoyo, tuvieron un comportamiento a la altura del reto, el cual fue llevado a buen término si juzgamos por una mortalidad global menor obtenida en comparación con la de épocas anteriores.

La aplicación de un conocimiento médico-científico sólido sin duda fue un factor determinante para sobrellevar esta temporada crítica. Y sin embargo, no me queda duda de que la presión, el estrés y el cansancio generados por una carga excesiva de trabajo, aunado a la frustración ocasional de situaciones particulares donde los resultados no fueron los esperados, pudiera haber afectado a más de una o uno. ¿Cómo lidiar con esto y al mismo tiempo mantener o mejorar la calidad/ calidez de la atención?

En la actividad hospitalaria cotidiana se toman innumerables historias clínicas; cada una de ellas representa el contacto del paciente con su médico o médica. Está precisamente en ella o él poder convertir dichas «historias» en verdaderas narrativas de las experiencias particulares vividas por todos para poder demostrar de esta forma, como en otras situaciones de la vida, que pacientes y médicos estamos juntos en las buenas y en las malas. Narrativas que muchas veces se realizan en mayor o menor grado de manera oral, en los pocos ratos de «semi-descanso" y que muchas veces les consideramos como plática de pasillo, anecdotario durante las reuniones sociales o simplemente chisme. Pero, ¿vale la pena transformar esas narrativas en algo más?

Otros lo han hecho sin problema y hago referencia a autores como Kraus y Palacios-Boix por ser médicosescritores o escritores-médicos cercanos a nosotros que nos muestran la posibilidad e importancia de combinar la actividad clínica con la narrativa médica y han publicado ejemplos claros de lo que estoy intentando establecer., ${ }^{1,2}$

En la última década, o un poco más, se ha enfatizado la importancia que la narrativa tiene en el trabajo médico cotidiano. La posibilidad de describir no solo signos y síntomas, si no de poder "contar la historia» como la siente el paciente y también poder incluir el impacto (físico, emocional, psicológico, espiritual) que la misma experiencia genera no solo en ella/él si no también en el «trabajador de la salud» para, de esta forma, quitarnos dicho epíteto laboral economicista y poder recuperar el concepto de «médico/médica» como alguien cuya 
preocupación va mucho más allá de llenar formatos, cumplir metas o generar una «victoria clínica».

Una medicina que respeta la narrativa necesariamente respeta la ortografía y la sintaxis, pero sobre todo respeta la adquisición de habilidades mediante la lectura literaria, la escritura reflexiva y la generación de un auténtico diálogo con pacientes, colegas y estudiantes de todos niveles. Finalmente, el conocimiento narrativo permite a uno comprender el significado de las historias mediante un acercamiento cognitivo, simbólico y afectivo con la situación singular de una persona (paciente) conforme se ha ido desarrollando en el tiempo (en su tiempo).

La doctora Rita Charon, ${ }^{3}$ ha propugnado mucho por impulsar el desarrollo de estas habilidades narrativas, las cuales considera un factor esencial para generar confianza, empatía y reflexión; características básicas del trabajo del médico y su relación con el paciente. Un verdadero modelo para la profesión de la medicina (en el sentido auténtico de profesarla).

$Y$ esto es importante contrastarlo con nuestro discurso habitual de considerar a la medicina como la aplicación del conocimiento producto de la investigación científica sobre los fenómenos que afectan al ser humano. Caer en el simplismo de ver nuestro trabajo como «ciencia aplicada» nos obnubila la posibilidad de ver el padecimiento de la persona que se encuentra frente a nosotros. Somos buenos para buscar la enfermedad, pero deficientes con el padecer (situación donde las mal llamadas «medicinas alternativas» nos sacan la partida).

Nuestra fascinación científica es imperativa, ya que sin ella no habría los múltiples logros con los que hemos ayudado a duplicar la expectativa de vida del ser humano en el último siglo de nuestra historia. Sin embargo, hay que reconocer que el trabajo médico tiene otra cara que conviene mucho voltear a ver.

El desarrollo de una narrativa médica nos puede ayudar, además, a poder difundir los conceptos científicos en los que se basa nuestro trabajo; con el paciente, para empezar, pero más con la sociedad. Debemos admitir que somos malos divulgadores de la ciencia como un todo y de la ciencia médica en particular. A veces nos conformamos con decir cosas como «¿Sabías que si el hombre saltara como una pulga podría llegar a la punta de la torre Latinoamericana? ¿Sabías que el pulmón humano contiene alrededor de 700 millones de alvéolos y que si los estirásemos equivalen a una cancha de squash?». ${ }^{4}$ Esto explica porqué la gente ve a los médicos-científicos, y a los científicos en general, como personas que vivimos de coleccionar datos insulsos.

Ser capaces de generar una narrativa sobre los hechos científicos médicos, y sobre todo de su meto- dología, va de la mano con la importancia de culturizar a la sociedad en cuestiones científicas. Por un lado, es primordial reconocer que ya no queda prácticamente nada que se pueda hacer sin ciencia (y su tecnología derivada); el transporte, la comunicación y hasta el entretenimiento dependen de ella pero, por encima de todo, la salud pública e individual. Por otro lado, tenemos la obligación de abatir el analfabetismo científico predominante en nuestra sociedad; entendido éste como la incapacidad de interpretar la realidad de la naturaleza sin recurrir a milagros, revelaciones, dogmas ni al principio de autoridad.

Luchar contra estos dos fenómenos permite intentar limitar lo que Marcelino Cereijido define como «cognicidio», matar el conocimiento. El conocimiento, dice, «... no es como la información que se puede guardar en la memoria de computadoras: se le debe poseer y usar. Todo organismo sobrevive siempre que sea capaz de interpretar la realidad».. ${ }^{5}$ El trabajo médico es un paradigma de la importancia de distinguir entre uso del conocimiento y mero acúmulo de información. Algo propuesto desde hace tiempo por el filósofo Alfred North Whitehead quien planteaba que «... un humano meramente bien informado constituye la aburrición más grande sobre la faz de la Tierra; ... pedazos de información solo adquieren valor si llegan a ser utilizados o por lo menos puestos dentro de una combinación fresca...». ${ }^{6}$

Cereijido va más allá al advertir que el hecho de no reconocer la importancia de la ciencia se puede atestiguar de manera cotidiana por «...poblaciones que padecen inundaciones cada temporal, carestía en la comida, medicamentos, agua, pero como le falta el conocimiento sobre ciencia no puede entenderlo, aunque se lo expliques. Y no sólo le pasa al campesino que vive en la sierra, le pasa al Estado".

Así, el adquirir habilidades narrativas permite relacionar no solo lo que le pasa al paciente con lo que nos pasa a nosotros como médicos, sino que incluye la posibilidad de narrar al paciente cómo es que hacemos nuestro trabajo. En otras palabras, enseñar al paciente sobre los fenómenos que le alteran en su entorno biológico, psicológico y social para encontrar la mejor forma de adaptarse y lidiar con su problemática, esa que, para muchos, constituye el concepto moderno de salud. ${ }^{7}$

$Y$ tal vez la narrativa pueda ser un reflejo no solo de una mejor profesión de la actividad médica, sino indicativo de una mejor ciudadanía capaz de influir en su entorno social más allá del aspecto de la salud.

Creo que es válida la analogía con la visión que ofrece Martha Nussbaum con respecto de las capacidades indispensables para el desarrollo de ciudadanos en una democracia y donde establece la premisa de que «el conocimiento no es garantía del buen compor- 
tamiento, pero la ignorancia ciertamente garantiza un mal comportamiento". ${ }^{8}$

En su libro propone la necesidad de impulsar tres capacidades primordiales al desarrollo de ciudadanos comprometidos con su sociedad y con el paradigma democrático:

a. El examen crítico de uno mismo y sus tradiciones: entendido como la vida examinada, en donde el razonamiento lógico predomine y permita la puesta a prueba, de manera continua, de la consistencia de los hechos y la exactitud de los juicios emitidos. La democracia requiere ciudadanos que piensen por sí mismos, reten sus presuposiciones y no difieran sus decisiones a la autoridad, el dogma o la costumbre/ tradición.

b. La habilidad de observarse a uno mismo como un ser humano conectado con todos los demás seres humanos: esto significa poder llegar considerarse ciudadanos universales y no meramente «ciudadanitos» de una localidad, región, área, país o grupo de algún tipo. Esta capacidad implica la posibilidad de comprender al otro, generar empatía y aceptar diferencias de raza, sexo, género, religión o formas de pensar.

c. El desarrollo de la imaginación narrativa: en otras palabras, la posibilidad de ver al mundo tal y como lo pudiera estar viendo una persona diferente de nosotros. Y poderlo describir, narrar, bajo la visión del «otro» a través de una actitud empática.

Todo esto que menciona Nussbaum sin duda atraviesa necesidades deseables para el gremio de la medicina y que frecuentemente se tocan en la literatura médica como la porción «humanista» a la que nos debemos. Y sin embargo, el concepto de narrativa médica, si bien ayuda a desarrollar el lado humanitario del trabajo médico (el que mira el bien del género humano, según el diccionario), más bien lo que busca es desarrollar en la medicina lo que verdaderamente se entiende como nuestro lado "humanista» en sus dos acepciones más importantes: cultivo o conocimiento de las letras humanas y doctrina o actitud vital basada en una concepción integradora de los valores humanos. Tal y como la plasmó Pérez Tamayo en su alocución en la Academia Nacional de Medicina de México al dictar la conferencia «Dr. Ignacio Chávez». ${ }^{9}$

La preparación de las médicas y los médicos que requiere nuestro país, y el mundo, sin duda atraviesa el manejo del conocimiento científico derivado ya no tanto de la anatomía, la fisiología, la histología, la embriología y la farmacología, si no de la microbiología, la biología celular/molecular, la bioquímica, la genética, la estadística y las técnicas epidemiológicas y de análisis de evidencia dentro del contexto de la metodología científica.

Pienso que la empatía, la reflexión, la profesión y la confianza son elementos inherentes a la medicina; sin adjetivos. Y más que una profesión, la medicina es una vocación; un llamado y no una carrera (visión muy neoliberal, donde ahora nos convierten en «trabajadores de la salud» y perdemos la categoría de médicos). Siempre he pensado que la currícula de medicina debe incluir un año de literatura (y otras artes), gramática, retórica, filosofía, ética, estética y muuucha reflexión personal (¿En vez del servicio social?). Solo así podremos llenar la mitad humanística del quehacer médico (siendo la otra mitad el conocimiento científico en que basamos nuestras acciones). Humanismo en el sentido descrito por Ignacio Chávez hace años y que fue mencionado arriba: el legajo cultural que nos permite entender y relacionarnos con el actor más importante de la obra médica, el paciente. Solo así podremos cumplir con ellas/ellos. Solo así lograremos escribir sus historias, sus narrativas -y las nuestras (en vez de llenar formatos de manera automatizada y para juntar puntitos certificatorios).

¿Cómo relacionarnos con las/los pacientes si estamos llenos de prejuicios, presuposiciones, malas concepciones, ideologías, dogmas y miedos que nos impiden actuar libremente? Sólo la literatura y demás ramas humanistas son capaces de movernos y evitar el marasmo que condenaba Sócrates: la vida sin reflexión no vale la pena vivirse.

Tal vez explorar los conceptos de narrativa médica nos ayuden a valorar su importancia. Sin duda su aplicación cotidiana repercutirá en la forma de hacer nuestro trabajo de una manera mejor; para nuestros pacientes y para nosotros mismos. Y, quién sabe, tal vez también nos ayude a reforzar nuestra participación y ser mejores ciudadanos en este incipiente e inacabado experimento democrático donde vivimos.

\section{REFERENCIAS}

1. Kraus A. Decir adiós, decirse adiós. México: Mondadori; 2013.

2. Palacios-Boix A. Las voces del cuerpo. México: Terracota; 2010.

3. Charon R. The patient-physician relationship. Narrative medicine: a model for empathy, reflection, profession, and trust. JAMA 2001;286(15):1897-1902.

4. Ochs M, Nyengaard JR, Jung A, et al. The number of alveoli in the human lung. Am J Respir Crit Care Med 2004;169(1):120-124. doi: 10.1164/rccm.200308-11070C

5. Cereijido M. Available from: http://comunicacion.cinvestav.mx/Inicio/Tabld/55/ArtMID/954/ 
ArticlelD/4/Marcelino-Cereijido-contra-el\%E2\%80\%9Ccognicidio\%E2\%80\%9D.aspx

6. Kohn A. The schools our children deserve. Houghton Mifflin; 1999. p.50. ISBN 0-395-94039-7.

7. Godlee F. What is health? BMJ 2011;343:d4817.

8. Nussbaum M. Not for profit: Why democracy needs the humanities. Princeton University Press; 2010.

9. Pérez-Tamayo R. Humanismo y medicina. Gac Med Mex 2013;149(3):349-353. $\triangle$ Correspondencia:

Dr. Patricio Santillán-Doherty, editor en jefe de NCT. Director Médico, Instituto Nacional de Enfermedades Respiratorias Ismael Cosío Villegas.

Calzada de Tlalpan 4502, colonia sección XVI.

México, D.F., 14080

Correo electrónico: patricio.santilland@gmail.com

El autor declara no tener conflicto de intereses. 